\title{
A VIOLA CAIPIRA NO DANDÔ: CULTURA POPULAR E MEIO AMBIENTE
}

\section{VIOLA CAIPIRA (TEN-STRING GUITAR) IN THE DANDÔ PROJECT: POPULAR CULTURE AND ENVIRONMENT}

\author{
Jussânia Borges Corrêa \\ Universidade de Brasillia \\ jubcorrea@yahoo.com.br
}

\section{Resumo}

Este artigo investiga o Projeto Dandô - Circuito de Música Dércio Marques, buscando compreender seus significados, bem como - papel da Viola Caipira nesse contexto. $O$ texto discute autores como Geertz (2012), Merriam (1964), Seeger (2008), Blacking (1974), Cambria (2015), Titon (2016), Vilela (2013), Brandão (2005, 2008, 2009), dentre outros. Foi realizada uma etnografia de dois espetáculos do projeto Dandô em Brasília, com os violeiros João Arruda e Victor Batista, e verificou-se que as músicas apresentadas transmitem um discurso de defesa da cultura popular e do meio ambiente. Este entrelaçamento entre música e natureza nos reporta à Ecomusicologia, que pode oferecer novas abordagens para enfrentar problemas antigos de música e cultura através de estudos conectados com as preocupações ambientais.

Palavras-chave: Cultura popular; Etnografia; Viola caipira; Ecomusicologia. 


\section{Abstract}

This paper investigates the Dandô Project - Dércio Marques Music Circuit, attempting to understand its meanings, as well as the role of the Viola Caipira in this context. The text discusses authors such as Ceertz (2012), Merriam (1964), Seeger (2008), Blacking (1974), Cambria (2015), Titon (2016), Vilela (2013), Brandão (2005, 2008, 2009), among others. Through an ethnographic study of two concerts within the Dandô Project, in Brasilia, it was verified that the songs performed, as well as the instrumental performances themselves, convey a discourse related to the defense of popular culture and of the environment. This interconnection between music and nature refers us to the field of Ecomusicology, which may offer new approaches to tackle old problems of music and culture through studies that are connected with environmental concerns.

Keywords: Popular culture; Ethnography; Viola caipira; Ecomusicology.

\section{Introdução}

Este trabalho, desenvolvido como parte de pesquisa mais ampla sobre os significados da viola caipira, foi realizado no âmbito da disciplina Etnografia da Música do Programa de Pós-graduação "Música em Contexto" da Universidade de Brasilia, durante o segundo semestre de 2015. Ao observar o Projeto "Dandô - Circuito de Música Dércio Marques," buscou-se compreender o universo que envolve essa nova forma de fazer e disseminar a cultura popular, seus significados, bem como o papel da Viola Caipira nesse contexto.

A importância do fazer cultural na formação de identidades do "povo" de uma nação é explicitada em Rocha enquanto "[...]'versões' da vida; teias, imposições, escolhas de uma 'política' dos significados que orientam e constroem nossas alternativas de ser e de estar no mundo" (ROCHA, 2004: 35).

Observa-se ainda o caráter cultural dinâmico abordado por Laraia (200l) nos falando que a cultura é resultante de um processo de aprendizagem, através da socialização, no qual o indivíduo se integra ao grupo com que convive. Laraia afirma que "os diferentes comportamentos sociais e mesmo as posturas corporais são assim produtos de 
uma herança cultural, ou seja, o resultado da operação de uma determinada cultura" (LARAIA, 200 I: 36).

Assim, e segundo Geertz, é importante que o estudo das culturas não se caracterize "como uma ciência experimental em busca de leis, mas como uma ciência interpretativa, à procura do significado" (CEERTZ, 2012: 4), ultimando pesquisadores e artistas a voltarem-se para o estudo dos significados do saber popular.

Brandão (2005) nos fala que a falta de entendimento do intercâmbio entre tudo que existe no universo, vem levando a humanidade a seguir uma trilha perigosa.

Se nas ciências da natureza, da pessoa e da sociedade há algo que esteja seguindo um rumo equivocado e perigoso, um dos motivos pode ser uma perda da compreensão das interações entre todas as coisas, entre todos os planos, entre o tudo do todo que somos, estrelas e flores, astros e pessoas, parte de uma mesma teia da vida, fração de uma mesma tessitura do universo (BRANDÃO, 2005: 19).

A experiência cotidiana de criação de culturas de vida solidária, biodiversa e sustentável deverá continuamente buscar responder muitas perguntas que ficam no ar, e que devemos repensar as ciências tendo por base a arte e o saber do povo (BRANDÃO, 2005).

Se o nosso trabalho tem sido o de uma busca solidária de felicidade humana através da cultura vivida, também, como o saber, a vida, a arte do povo, e o seu poder ancestral de união e de luta, como inserir isso em um trabalho voltado a repensar as ciências e as tecnologias com que pensamos nós mesmos e nosso mundo, em busca de uma nova lógica da natureza e de uma nova ética do ambiente? (BRANDÃO, 2005: 24).

Somos os únicos seres capazes de tornar um deserto reverdecido e reinventar uma Terra inesgotável, assim como também "somos os únicos seres que podem destruir o planeta em que vivemos e a "navecasa" em que vagamos, geração após geração, pelo universo" (ibid). A conscientização e educação ambiental se tornam ações primordiais, 
para colaborar na construção de um novo futuro baseado em ações ecológicas sustentáveis!.

universo musical abordado pela viola caipira e pela música como um todo, exprime toda uma série de significados sociais, como afirma Merriam (1964) sobre a importância da função da música para compreendermos o funcionamento de uma sociedade:

As funções e as utilizações de música são tão importantes quanto as de qualquer outro aspecto da cultura para a compreensão do funcionamento da sociedade. A música está inter relacionada com o resto da cultura; ela pode efetivamente moldar, fortalecer e canalizar comportamentos sociais, políticos, econômicos, linguísticos, religiosos, entre outros. Letras de músicas podem revelar muitas coisas sobre uma sociedade, e a música é extremamente útil como um meio de análise de princípios estruturais² (MERRIAN, 1964: 15).

O projeto "Dandô - Circuito de Música Dércio Marques" faz parte de um movimento de reavivamento da cultura popular que vem crescendo no Brasil nas últimas décadas, por meio de resistências de grupos locais, performances em espaços diversos, pesquisas, encontros de cultura, festivais, bem como de músicos que compõem para diversas trilhas sonoras, espetáculos, documentários, novelas, mostras e filmes, valorizando a música regional. A Viola Caipira está inserida neste contexto de resistência cultural, sendo por excelência, um instrumento musical do meio rural, difundido em todo país, traduzindo formas lúdicas de socialização (MESTRES DA VIOLA, 2011). Está presente em diversas manifestações tradicionais da cultura popular, como a dança de São Gonçalo, as Folias de Reis, a festa do Divino, o cateretê, os desafios, o fandango, o cururu, a catira, a moda de viola, a toada, o batuque, o samba de roda e o rasqueado, compondo uma riqueza de diversidade de estilos e sotaques.

I Em 1987, por meio de uma pesquisa de opinião, constatou-se que 90\% dos brasileiros vivendo nos antigos domínios da Mata Atlântica nunca tinham ouvido falar dela, "o modo do seu desaparecimento foi apagado do banco de memória até de sua classe média" (BRANDÃO, 2005: 69).

2 The functions and uses of music are as important as those of any other aspect of culture for understanding the workings of society. Music is interrelated with the rest of culture; it can and does shape, strengthen, and channel social, political, economic, linguistic, religious, and other kinds of behavior. Song texts reveal many things about a society, and music is extremely useful as a means of analysis of structural principles (MERRIAN, 1964, p. 15). 
Nesse sentido, este trabalho faz uma etnografia de dois espetáculos do projeto musical Dandô, em Brasília, com os violeiros João Arruda e Victor Batista, e busca compreender e identificar os significados musicais de suas performances na Viola Caipira e a interação com a plateia presente, bem como os significados para os ouvintes. Além das observações durante os espetáculos, foram realizadas algumas conversas informais com alguns músicos e membros da plateia participante.

\section{O Projeto Dandô - Circuito de Música Dércio Marques}

O projeto "Dando - Circuito de Música Dércio Marques" foi idealizado em 2013 pela cantora, compositora e pesquisadora de raízes musicais, a paulistana Kátya Teixeira, e busca uma interação musical por todo o país, por meio do intercâmbio entre artistas de várias regiões, como uma caravana musical que já passou por mais de 30 cidades brasileiras. Em cada edição um artista local atua como anfitrião, recebendo e abrindo o espetáculo para o convidado, ocorrendo um bate papo entre artista(s) e plateia fechando a apresentação. $\bigcirc$ projeto faz uma homenagem ao músico Dércio Marques, nascido em Uberaba/MG, falecido em junho de 20 12. Durante sua carreira, Dércio uniu cantadores de toda parte, de várias gerações, estilos e culturas.

O Circuito Dandô foi vencedor do "Prêmio Brasil Criativo" na categoria música, promovido pelo Ministério da Cultura, em 2014, e em 2015 foi lançado o CD "DANDO - Circuito de Música Dércio Marques - um canto em cada canto do Brasil" que recebeu reportagens como a do Jornal Caleria - A Tribuna (SP):

São pesquisadores interessados nos sons brasileiros que insistem em não morrer, apesar da devastadora ação da indústria cultural. $\bigcirc$ nome do evento, inspirado em Dércio Marques, não poderia acertar melhor no sentido da homenagem. Dércio foi um grande menestrel brasileiro que deixou uma obra insuperável e imprescindivel, circulou por toda parte do Brasil e da América Latina, recolhendo os cantos e sons que ouvia dos povos mais longínquos e remotos, desde as canções e os toques de violão do argentino Atahualpa Yupanqui até o Coral das Lavadeiras do Vale do Jequitinhonha entre uma infinidade de outras manifestações (BITTENCOURT, 2015). 
Inicialmente, a motivação para este trabalho surgiu em agosto de 2015, durante o show de Marcelo Taynara, artista de Uberaba/MC, no Circuito Dandô em Brasília, que muito impressionou a plateia por trazer em seu trabalho elementos de sua descendência negra e indígena, denotando ainda uma influência do clube da esquina e do congado. Além de compositor, arranjador e instrumentista autodidata, Marcelo possui uma marca peculiar agregando em sua performance efeitos vocais de pássaros, cachoeiras e outros sons da natureza e de percussão.

Com o intuito de investigar outras performances de artistas participantes do Dandô, uma análise etnográfica mais detalhada foi realizada em setembro e novembro de 2015 em outros dois espetáculos com os violeiros João Arruda e Victor Batista, principalmente por serem estes importantes tocadores do instrumento Viola Caipira, que buscam levar uma mensagem voltada para cultura popular e o meio ambiente.

\section{Dandô em Brasília}

No ano de 2015, em Brasília/DF, o Circuito Dandô foi realizado uma vez ao mês às terças feiras na Casa da Cultura Brasília, um espaço que funciona na Quadra 703 da Asa Norte, na casa da cantora e professora de Canto Erudito Janete Dornelas, um local aberto para música cultura e arte, aulas particulares e em grupo, pequenos espetáculos e eventos.

No projeto Dandô, em um clima descontraído, como um sarau ou reunião de cantoria, a plateia vem constituindo-se de violeiros, músicos, jornalistas, ambientalistas, universitários, amantes da música popular brasileira, bem como de amigos e familiares dos artistas, onde todos são levados a participar do show de forma interativa.

\section{O Dandô com João Arruda}

No dia de 22 de setembro de 2015, o violeiro João Arruda, nascido em Campinas/SP, foi recebido na Casa da Cultura Brasilia. Além de multi-instrumentista, cantor, pesquisador e produtor fonográfico, João Arruda mescla em seu trabalho composições de sua autoria e cantigas e brincadeiras do folclore brasileiro e de compositores que se expressam por meio da cantoria e da cultura popular, como João do Vale (MA) e Elomar Figueira de Melo (BA). 
O violeiro Domingos de Salvi foi anfitrião que abriu o show tocando algumas músicas instrumentais na viola caipira, e João Arruda, entrando pela plateia, na sequência cantou a última dessas músicas instrumentais, um Boi do Maranhão: Cheguei / com meu batalhão de ouro / vim trazer prazer de São João / Eu ainda estou firme / e meu povo / faz tremer o chão / com pandeiro e matraca / maraca de prata na mão3.

Além da Viola Caipira e da voz, João Arruda toca um tambor grande, e usa gungas atadas em seus tornozelos: conjuntos de recipientes como pequenas latinhas/chocalhos, típicas das festas de congado, moçambique, e reisado de Minas Cerais. Durante o show, em algumas canções típicas da cultura popular, João sapateia marcando o ritmo com o som das gungas, incentivando a plateia que o acompanha com palmas e voz. Assim como ocorre nas manifestações de grupos folclóricos, não só os músicos participam, como toda a comunidade envolvida.

Em outro momento, João fala de sua viola de cabaça fazendo um trocadilho, dizendo que ela foi "composta" pelo amigo luthier ${ }^{4}$ e compositor Levi Ramiro que foi quem "construiu" a próxima música que ele cantou tocando nessa viola: Toco viola de noite, aprecio o firmamento I viola tem som de bicho / quando traz um guizo dentro, / é coruja que arrepia quando solta o seu lamento. / Viola vem lá do mato, / lá do meio da quiçaça / de cocho, de buriti, / de madeira ou de cabaça / [...]. João conta que esta é uma das músicas de seu $2^{\circ}$ CD Venta Moinho, que foi gravado em 2013, na casa da mata do Sítio Rosa dos Ventos ${ }^{5}$ em Pocinhos do Rio Verde, nas montanhas do sul de Minas Gerais, em meio ao som do ambiente natural, pássaros e bichos.

Durante sua performance, João conta diversos "causos" relacionados ao repertório musical e à sua trajetória cultural de contato com a cultura popular, e na sequência convida ao palco o violeiro mineiro Erick Castanho. Juntos cantam Chão de Reis', seguida de Chapéu de

3 A música "Maracá de Prata" foi composta por Humberto Barbosa Mendes, falecido em 20 de janeiro de 2015 em São Luiz do Maranhão, conhecido como Humberto de Maracanã, do Bumba Boi de Maracanã.

4 Profissional que trabalha com a arte de construção e manutenção de instrumentos musicais.

$5 \bigcirc$ Sítio Rosa dos Ventos é uma proposta de pousada solidária chamada também pelo dono, o antropólogo Carlos Rodrigues Brandão, de Casa de acolhida. Livro livre consta no site do sítio, com obras de Brandão. Disponível em: http://www.sitiodarosadosventos.com. brl. Acesso: 08/09/2016.

6 Composição de João Arruda, João Mendes e Cassiano Nogara.

\section{3}


Palha': O meu chapéu é de palha / Meu sinhô, buritizeiro / Minha cantiga é de vento / Meu amor, verdadeiro. / Minha casa rebocada / Por dentro e por fora não / Por dentro cravos e rosas / Por fora, manjericão. I Nasce a lua, nasce o sol / Estrela matutina / So tiro o meu chapéu / Pra você, sinhá menina [...].

João Arruda prossegue fazendo diversas quadras do sertão, de domínio público adaptadas pelo violeiro mineiro Josino Medina, e finalizando a apresentação chama ao palco o violeiro organizador do Dandô em Brasília, Pedro Vaz, seu anfitrião Domingos de Salvi, e a cantora percussionista Inez Cabocla. Pedro toca uma violinha pequena feita de buriti ${ }^{8}$ e Inez canta e toca tambor de folia, todos juntos em animada cantoria, com participação da plateia.

\section{O Dandô com Victor Batista}

Em 17 de novembro de 2015, Pedro Vaz foi o anfitrião recebendo o violeiro mineiro Victor Batista na Casa da Cultura Brasília. Victor é de Belo Horizonte e mora atualmente em Pirenópolis/CO. Pedro abre com três músicas instrumentais: uma dos Beatles; uma composição própria; e Luzeiro do violeiro compositor Almir Sater.

Victor sai do camarim localizado atrás da plateia e segue até o palco pedindo licença para entrar cantando uma Folia de Reis seguida de trovas de domínio público adaptadas por ele. A plateia é convidada por Victor a acompanhar uma das trovas com ritmos de palmas que ele ensina. A seguir Victor canta Círculo das ilusões?, a canção que inspirou Kátya Teixeira para o nome do Projeto Dandô, e que foi composta para Dércio Marques: Dandô ô dandei /olha o vento que brinca de dandá / Ele vem pra levar as andorinhas ou quem sabe a canção pra uma janela / Saciar o ipê que se formou e roubar suas flores amarelas / Senhor vento, eu não quero ser primeiro, mas preciso uma ponga pelo ar / Quero ser bandoleiro como vós e no balanço do mar poder cantar $/[. .$.$] .$

7 Composição de João Bá e Luiz Carlos Bahia.

8 Palmeira nativa do Cerrado, abundante nas veredas.

9 Esta composição de João Bá e Klécius Albuquerque foi gravada por alguns músicos, dentre eles, Dércio Marques em seu álbum duplo Segredos Vegetais (vinil - 1988, CD - 1993). 
Depois de cantar uma composição de sua autoria Manchete do Tico-tico, Victor conta um causo sobre São Conçalo do Amarante, um santo de Portugal protetor dos violeiros. Segue tocando na viola duas músicas instrumentais, tradicionais do cancioneiro caipira, Saudade da minha terralo e Rio de Lágrimas"l, e a plateia de forma espontânea acompanha cantando junto. Victor comenta então sobre a recente tragédia ambiental em Minas Gerais, na cidade de Mariana, lamentando as populações das cidades e comunidades que dependem do rio doce contaminado com a lama e minério da barragem que rompeu no início do mês inundando a cidade de Bento Rodrigues e toda a região ao redor.

Seguindo a apresentação, o violeiro recita um poema falando de flores, matas, rios, cerrado das nascentes, gabiroba, cajuzinho, com o refrão: vivo e defendo a natureza. Victor fala um pouco sobre a Serra dos Pirineus em Pirenópolis, que ele conta ser um santuário de duas nascentes, da bacia do Paraná e da bacia do Tocantins, vai desaguar em Mar del Plata, na divisa do Brasil com a Argentina. $\bigcirc$ violeiro comenta que esse fato só pode dizer que tudo está ligado e nós energeticamente estamos todos ligados, o que se faz aqui vai refletir depois, e que um exemplo está com as mudanças climáticas e a chuva que demora.

Para finalizar o show, todos cantam juntos com a plateia a música de domínio público Riacho de Areia'2: Beira-mar, beira-mar novo / Foi só eu é que cantei / O beira-mar, adeus dona / Adeus riacho de areia. I Vou remando minha canoa [...].

\section{Conversando com a plateia}

Antes do início e após o término do Dandô com Vitor Batista, realizado na Casa da Cultura Brasília em novembro, ocorreu uma conversa informal com algumas pessoas da plateia.

Conversando primeiramente com Inez Cabocla, 54 anos de idade, uma das organizadoras do Projeto Dandô em Brasilia, cantora e artista de cultura popular, ela falou da importância da música de Dércio

\footnotetext{
10 Composta pela dupla Goiá (1955-1981) e Belmonte (1937-1972).

11 Composta por: Lourival dos Santos, Tiço Carreiro, e Piraci.

12 Essa música de domínio público do Vale do Jequitinhonha/MG foi recolhida e adaptada por Frei Chico e Lira Marques, gravada pelo Coral Trovadores do Vale, Dércio Marques e diversos outros músicos.
} 
Marques em sua vida, e que o conheceu há 40 anos, junto com o trabalho de Elomar, a partir daí acompanhou o trabalho deles, inclusive criando seus filhos com a música de Dércio. Inez informa que este artista era um peregrino, participava de manifestações da cultura popular nas comunidades e apoiava o trabalho de quem não tinha condições de divulgar, e complementa dizendo que o trabalho da Kátya é mais ou menos nesse formato, visando a continuidade do trabalho do Dércio.

Quando conversei com um jornalista de 48 anos de idade que estava registrando o evento, ele disse se considerar antes de ser jornalista, um apaixonado pela cultura popular, e explicou um pouco sobre a forma solidária e acolhedora de como funciona o Dandô, que envolve várias pessoas, colaborando com a hospedagem, passagens, alimentação. Walter ressaltou a importância dessa nova forma de se fazer a cultura popular, onde a participação é de um público de qualidade, que quer conhecer e que vai passar para frente uma cultura que não pode se perder, contrapondo aos interesses das grandes empresas para grandes públicos.

Já uma jovem estudante de antropologia na UnB expressou o quanto a música toca sua alma, e diz se sentir atraída pelo som da Viola Caipira, relacionando-o com a terra, admirando a versatilidade do instrumento, bem como a beleza das músicas, além de gostar muito da natureza e do estilo musical do Projeto Dandô.

anfitrião do Dandô, Pedro Vaz, 27 anos, violeiro, formado em Licenciatura em Música na UnB, organizador com Inez do Projeto Dandô em Brasilia, falou sobre a importância da convivência e aprendizado musical que é proporcionada em sua experiência junto aos músicos integrantes do Dandô, comentando que considera esse processo como uma escola, pois muitos deles têm muita bagagem e muita informação.

\section{Breve discussão}

A cultura popular e a música regional no Brasil vêm lutando para se manterem vivas por meio de iniciativas como esta do projeto Dandô. Assim como aborda Rocha (2004), em várias sociedades, o etnocentrismo se ajusta com a lógica do progresso, com a ideologia da conquista e da riqueza, com uma forma de viver que exclui a diferença. Por isso, "conhecer a diferença, não como ameaça a ser destruída, mas como 
alternativa a ser preservada, seria uma grande contribuição ao patrimônio de esperanças da humanidade" (ROCHA, 2004: 30).

Renovar e reciclar sempre nossos conhecimentos e pesquisas sobre a cultura brasileira dentro das peculiaridades de cada região é importante para enriquecer o campo de conhecimento acadêmico. Como afirma Rice (2008), temos que buscar um novo fundamento filosófico para nossas pesquisas e tentar mediar as divisões que herdamos do lluminismo ocidental e das tradições científicas pré-modernas. Observa-se no projeto Dandô, a valorização e divulgação da variedade cultural brasileira.

As canções apresentadas nos shows do Dandô nos levam muitas vezes a interessar conhecer uma determinada cultura. Pesquisas e trabalhos nesse sentido podem levar também a uma revitalização de uma cultura local, assim como nos explica Cambria (2015):

Se a diferença pode chegar até nós mediada pela indústria cultural ou personificada nos indivíduos ou grupos entre nós que consideramos como "outros" (não importa se nossos compatriotas ou estrangeiros), nós também viajamos para encontrá-la em outros lugares (ou, nos lugares do "Outro"). [...] Este trabalho pode, às vezes, oferecer também a oportunidade de revigorar as culturas em questão (CAMBRIA, 2015: 09).

Cambria (2015) nos dá o exemplo de um projeto cujo objetivo original era a organização de espetáculos culturais em uma região, a serem vendidos e consumidos pelo turismo cultural. "Adotando estratégias participativas de pesquisa, e colocando em diálogo etnomusicologia, desenvolvimento comunitário e ação ambiental, seus significados mudaram significativamente, favorecendo a reconstrução da própria comunidade e seu empoderamento" (CAMBRIA, 2015: 10). A proposta do Dandô funciona circulando os espetáculos em várias regiões do Brasil, semeando, valorizando e divulgando a cultura regional, estimulando ações culturais de comunidades locais, bem como, de órgãos públicos ou privados.

Assim como aborda Oliveira Pinto (2012), a música traz à tona fenômenos diversos, por vezes inesperados e não necessariamente acústicos através da uma performance ou acontecimento sonoro, podendo

\section{7}


afetar participantes individuais e assim influenciar em decisões nas esferas não-musicais.

As mensagens musicais do Dandô reportam não só à valorização da cultura brasileira de raiz, como também ao meio ambiente e a nossa sobrevivência no planeta. Como menciona Vilela (2013), os valores faltantes na cidade, como a solidariedade, a preocupação maior com o ser que com o ter, e um jeito tranquilo de ver o mundo, colaboram para reacender culturas brasileiras ligadas ao campo.

Com o neoliberalismo, a obra de arte se transforma em mero produto de vendagem, e paralelamente com a globalização, ocorre um efeito colateral aliado a ideia ecológica de preservação das diversidades ambiental e cultural e também a desilusão com o 'sonho da cidade grande' fizeram as pessoas voltarem seu olhar para o campo de forma menos dicotômica [...] (VILELA, 2013: 118 ).

Além do pensamento ecológico que também defende a preservação da diversidade cultural, Vilela (2013) nos fala de outros fatores reenraizantes importantes.

Apesar de toda a situação de desenraizamento causada pela monocultura no campo e pela monocultura na cidade a partir da supressão das culturas locais em troca de uma cultura de consumo, sazonal, temos presenciado um renascer das culturas e dos valores locais em várias partes do país e do mundo. [...] Também dissemos que a desilusão com o sonho da cidade grande tem feito as pessoas, agora impossibilitadas de retornar às suas raízes geográficas, buscarem valores que nortearam outrora sua formação. [...] (VILELA, 2013: 147).

Verifica-se que as músicas e canções apresentadas nas edições do Dandô possuem significados além do som e remetem muitas vezes à estória de vida de cada ouvinte que se identifica com os causos cantados pelos artistas, e, muitas vezes, acompanha as canções cantando junto com os músicos durante a performance, o que também se confirmou por meio das entrevistas realizadas com músicos e participantes nos dois eventos. Seeger (2013) nos chama a atenção para esse ponto abordando os efeitos exercidos pelas canções sobre as pessoas como não estando limitados aos efeitos físicos dos sons, podendo fazer relembrar sua terra, sua juventude, alegrias ou perdas da vida. Seeger 
afirma que "não devemos procurar pelos grandes efeitos dos sons em sua ação física, mas no coração humano" (SEECER, 2013: 244).

Segundo Blacking (1974), deve haver relações estruturais próximas entre a função, o conteúdo, e a forma da música, e ainda afirma que "se queremos avaliar o valor da música na sociedade e na cultura, devemos descrevê-la nos termos das atitudes e dos processos cognitivos que a sua criação envolve, e das funções e dos efeitos do produto musical na sociedade" (BLACKING, 1974: 37).

O repertório musical que vem acompanhando o projeto Dandô, do qual a Viola Caipira é instrumento quase sempre presente, é recheado de estórias de amor e convivência com a natureza, como mostram as letras das canções apresentadas neste trabalho. $\bigcirc$ Dandô então passa a ter um papel também de disseminar através da musica valores socioambientais como o cuidado com a nossa mãe Terra - nossa casa, nossa morada. Como afirma o físico, teórico ecologista Fritjof Capra (2002), tudo nesse universo está interligado em uma teia infinita, entre plantas homens animais, a "teia da vida", cujo equilibrio se encontra ameaçado pelos impactos sociais e ecológicos.

A preocupação para uma nova consciência ambiental vem permeando diversos setores de nossa sociedade, bem como é tema de debate em encontros ecológicos e culturais que ocorrem no país e no mundo em defesa da vida na Terra e da diversidade cultural dos povos em que nela vivem. Tais manifestações são importantes para colaborar em frear os sérios desajustes sociais e de sustentabilidade do meio ambiente, e a arte pode desenvolver um importante papel nesse sentido. Japiassu (1975) nos alerta que diante do monopólio da racionalidade científica, se faz necessário reconstituir a imagem quebrada do homem, reforçando sua identidade pessoal e sua relação com os outros seres vivos, pois a ciência e a manipulação técnica sobre a natureza vêm causando danos com prejuízos incalculáveis, afetando diretamente a qualidade e sobrevivência de vida em todo planeta.

Propondo uma conexão intersubjetiva feita através do som, Jeff Todd Titon (2016) aborda como uma ontologia sonora pode conduzir a uma epistemologia relacional e a uma atividade comunitária, em contraste com a consciência instrumental e racionalidade econômica. A partir daí, uma comunidade sonora pode se apresentar bem integrada, com trocas sociais e culturais, atuando de forma cooperativa e não 
competitiva, cujas trocas econômicas tendem a manter relacionamentos pessoais ao invés de impessoais e contratuais, contrapondo ao individualismo, egoísmo e conveniências (Titon, 2016).

Uma ontologia sônica da Viola Caipira relacionada à terra é um exemplo prático dessa abordagem, apontando para um comportamento ecológico dos violeiros por meio de suas composições instrumentais e cantadas, chegando a desenvolver um papel importante de conscientização ambiental, seja de forma proposital ou apenas por se apresentar intrínseca ao toque da viola.

Enquanto disciplina acadêmica recente, a Ecomusicologia preocupa-se com o estudo da música, cultura e natureza, e considera as questões musicais e sonoras de forma inter-relacional à ecologia e ao meio ambiente em seu estado natural. Como em várias composições do universo musical da Viola Caipira, o entrelaçamento vida/natureza é um forte aspecto que acompanha e caracteriza estas manifestações, de forma intrínseca e orgânica, formando um campo vasto de conhecimento a ser pesquisado.

\section{Considerações finais}

Projeto Dandô - Circuito de Música Dércio Marques, vêm também colaborar na construção de valores ecológicos e sociais, expressos como, por exemplo, nas mensagens musicais, e na solidariedade e vivências entre músicos e participantes do projeto, assim como nos fala Rocha, "O plano onde as diferenças se encontram, onde o "eu" e o "outro" se podem olhar como iguais, onde a comparação se traduz num enriquecimento de possibilidades existenciais, é o plano mais amplo e profundo de um humanismo do qual o etnocentrismo se ausenta" (ROCHA, 2004: 37).

Pesquisar o saber, o cantar e o viver de nosso povo, leva à reflexão sobre a importância de se conhecer esse universo não privilegiado em nossa sociedade. Brandão (2009) diz que ainda conhecemos pouco de nossas manifestações culturais:

(...) entre os dias da vida cotidiana e os da festa, como as lendas, os contos, os mitos, e mais ritos e rituais dos festejos e das celebrações, entremeadas com as criações de artes e artesanato de múltiplas culturas sem fundo, de tão férteis 
e fecundas, sobre as quais, depois de tanto tempo e tanto estudo, conhecemos ainda tão pouco (BRANDÃO, 2009:

18).

Assim como também, é possivel sensibilizar as pessoas em busca de uma sociedade sustentável para frear o risco de destruição, como afirma Brandão (2008):

A proposta de uma sociedade sustentável participa de todo um conjunto de palavras, ideias e ideários que sonham transformar mentes e sensibilidades de pessoas. Mudanças de padrões e modos de ser e viver, de sentir e pensar, que aos poucos nos convertam à uma compreensão de que os desejos pessoais e coletivos de conquista desenfreada e de uma equivalente sede de acumulação de bens e de poderes nos conduzirão a uma inevitável competição destruidora (BRANDÃO, 2008: 137).

Nesse sentido, por meio da investigação etnográfica dos dois espetáculos do projeto musical "Dandô" em Brasilia, respectivamente o dos violeiros João Arruda e Victor Batista, verificou-se nas composições e performances a construção de um discurso em defesa da cultura popular articulada àquela em defesa do meio ambiente disseminando preocupações pelo ecossistema, como apresentado no campo epistemológico emergente da Ecomusicologia em cujo quadro teórico-metodológico este trabalho se enquadra.

\section{Referências bibliográficas}

BITTENCOURT, Julinho. Projeto premiado chega ao disco. MPB Jornal Caleria. A Tribuna. Santos: 6 de maio de 2015.

BLACKING, John. "Música na sociedade e na cultura”. In: BLACKING, John. How Musical is Man? Seattle and London: University of Washington Press, 1974. p. 24-37 [Traduzido por Guilherme Werlang, não publicado].

BRANDÃO, Carlos Rodrigues. O saber, o cantar e o viver do povo. $19^{\circ}$ volume. São Paulo: Coleção Cadernos de Folclore, 2009.

Minha casa, o mundo. Aparecida, SP: Ideias \& Letras, 2008.

\section{1}

REV. TULHA, RIBEIRÃO PRETO, v. 2, n. 2, p. 77-93, jul.-dez. 2016 
. As Flores de Abril. Movimentos sociais e educação ambiental. Campinas: Autores Associados, 2005.

CAMBRIA, Vicenzo. "Diferença: uma questão (re)corrente na pesquisa etnomusicológica”. Música e Cultura: revista on-line de etnomusicologia, n. 3, 2008. Disponível em: http://musicaecultura.abetmusica.org. br/index.php/revista/article/view/108. Acesso: 23/08/2015.

CAPRA, Fritjof. As conexões ocultas - ciência para uma vida sustentável. São Paulo: Editora Pensamento-Cultrix LTDA, 2002.

CEERTZ, Clifford. "Uma descrição densa: por uma teoria interpretativa da cultura". In: CEERTZ, Clifford. A Interpretação das Culturas. Rio de Janeiro: LTC, 2012. p. 03-21.

JAPIASSU, Hilton. Introdução ao Pensamento Epistemológico. Rio de Janeiro: Livraria Francisco Alves Editora S.A., 1975.

LARAIA, Roque de Barros. Cultura: um conceito antropológico. Rio de Janeiro: Jorge Zahar, 2001.

MERRIAM, Alan P. Capítulos 1 e 2. The Anthropology of Music. Evanston: Northwestern University Press, 1964.

MESTRES DA VIOLA, Uma viagem musical pelo rio São Francisco. Associação Nacional dos Violeiros do Brasil, Belo Horizonte: 20 11 . I DVD.

OLIVEIRA PINTO, Tiago de. "Som e música. Questões de uma antropologia sonora". Revista de Antropologia, São Paulo, v. 44, n. I, 200 l. Disponivel em: http://www.scielo.br/scielo.php? script=sci_arttextEpi-

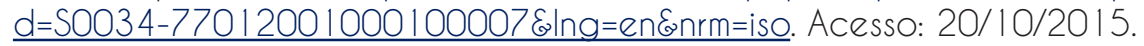

RICE, Timothy: "Toward a Mediation of Field Methods and Field Experience in Ethnomusicology". In: BARZ, Gregory e COOLEY, Timothy J. Shadows in the field: new perspectives for fieldwork in ethnomusicology. Oxford e New York: Oxford University Press, 2008. p. 25-4 1. 2004.

ROCHA, Everardo P. $\bigcirc$ que é etnocentrismo. São Paulo: Brasiliense, 
SEECER, Anthony. Etnografia da música. Tradução de Giovanni Cirino. Revisão Técnica de André-Kees de Moraes Schouten e José Clebson Vieira. Cadernos de campo, São Paulo: 2008. n. 17, p. 1-348. Disponivel em: http://www.revistas.usp.br/cadernosdecampo/article/download/47695/51433. Acesso: 24/09/2013.

TITON, Jeff Todd. Toward a Sound Ecology. Fall 2016 Conference of the American Musicological Society - Southwest Chapter. Abilene Christian University-City Square in Downtown Dallas: 511 N. Akard, Suite 200, Dallas, TX 7520. Saturday, October 1, 2016.

VILELA, Ivan. Cantando a Própria História - Música Caipira e Enraizamento. São Paulo: Edusp - Editora da Universidade de São Paulo, 2013.

\section{Sobre a autora}

Jussânia Borges Corrêa estudou no Conservatório Estadual de Música Renato Frateschi em Uberaba - MC. Especializada em Ciências Sociais no Trabalho em Comunidades pela Universidade Federal Rural do Rio de Janeiro - UFRRJ, atuou 14 anos com povos indígenas, principalmente com a Kàpey - União das Aldeias Krahô e a Escola Agroambiental Catxêkwyj (Terra Indígena Krahô - TO), nas áreas: Educação ambiental, Uso sustentável do Cerrado e Segurança alimentar. Formada em Licenciatura em Música pela Universidade de Brasília - UnB e no Curso Técnico em viola Caipira pelo Centro de Educação Profissional Escola de Música de Brasília - CEP/EMB. Atualmente é aluna de mestrado do Programa de Pós-graduação "Música em Contexto" do Departamento de Música/ Instituto de Artes da Universidade de Brasília - UnB, na área de concentração "Teorias e Contextos em Musicologia".

Recebido em: 09/09/2016

Aprovado em: 25/01/2017 